\title{
Experimental design and modeling of removal of organic matter and nutrients in the OMW by calcium bentonite
}

\author{
Hanane Ait Hmeid ${ }^{1, *}$, Mustapha Akodad ${ }^{1}$, Mourad Baghour ${ }^{1}$, Abdelmajid Moumen ${ }^{1}$, Ali Skalli $^{1}$, and Ghizlane Azizi ${ }^{1}$ \\ ${ }^{1}$ Laboratory Observatory of the Marchica Lagoon of Nador and Limiting Regions (OLMAN-RL), Multidisciplinary Faculty of Nador, \\ Mohamed 1st University, 60700 Nador, Morocco.
}

\begin{abstract}
The present work reports the application to reduction of the organic matter and nutrients in oil mill liquid waste (OMW), using the natural calcium bentonite from Morocco as adsorbent. The margine is characterized by a high concentration of low biodegradable and highly toxic organic matter. In order to evaluated the reduction capacity of bentonite to remove organic matter and nutrients, characterization mineralogical, chemical and also morphological of adsorbent were conducted. During the experiment and in the scenarios studied, all the total of parameters adsorbed was strongly depend on the percentage of bentonite. While, the percentage of $\mathrm{pH}$ of OMW was gradually decreased from 4.03 to 8 . 04. The COD concentrations were decreased from 172.72 to $29.71 \mathrm{~g} / \mathrm{l}$, and also the phosphorus concentrations were decreased from 1.16 to $0.29 \mathrm{~g} / 1$. The electrical conductivity decrease in this work from 16.93 to 0.17 $\mathrm{mS} / \mathrm{cm}$. This present work proves that calcium bentonite is an effective adsorbent for the elimination the nutrients and organic compound.
\end{abstract}

\section{Introduction}

Clay generally refers to a mineral substance consisting mainly of clay minerals and is widely used in a wide range of applications [1,2]. Clayey rocks are named after the bentonite was discovered in 1888 at Fort Benton, Roche-GReek area in Wyoming (USA) [3, 4]. Bentonite is a volcanic rock that results from alteration and hydrothermal transformation of ashes from glassrich volcanic tuffs resulting in the neoformation of clay minerals $[5,6]$. They contain more than $85 \%$ minerals of the montmorillonite family with elements in the form of impurities from other types of clay (illite, kaolinite, etc.), and non-clay minerals (quartz, feldspar, gypsum, calcite, etc.) [7]. They are a key component in the formulation of ceramic products, cement, drilling fluids, molding sands. They are also used as a texture agent in paints, paper bleaching agent, or reinforcing agent for polymer-based plastic materials. Clays are also found as catalysts, particularly in the pharmaceutical industry, or as membranes for filtration processes in the food industry [8]. In past studies, researchers mostly studied the development of new procedures for the immobilization of pollutants in aqueous media with respect to soil, have shown that swelling clays show a high affinity for a particular class of adsorption of organic and inorganic pollutants [9-11].

In the recent years, the use of bentonite has received broad scientific acceptance in environmental researches due to its high decolorization power and toxicity reduction capacity [12-16].
The bentonite used in this study is calcic in nature, a very high liquidity limit $[17,18]$, characterized by a porosity and permeability moderately high, with clay fraction of $9.09 \%$, the silt fraction of $58.69 \%$ and a sand fraction of $32.21 \%$ [19]. It was shown that the high water retention capacity with water content from $38.78 \%$, the $\mathrm{CaCO}_{3}$ content were very low (11\%) [20]. The aim of this study was to evaluate the potentiality of calcium bentonite for the removal of organic matter and nutrients.

\section{Experimental}

\subsection{Material and instrumentation}

Natural bentonite was applied from deposits located in the Nador city (North-East Morocco) (Fig. 1), and used without any prior activation. The margine used in this work come from a semi-modern oil mill located about 60 $\mathrm{km}$ from the city of Nador. The main computer tools used are ArcGIS-version 10.5 (developed by ESRI: Environmental Systems Reasearch Institue) and Google Earth Pro.

The different characteristics of the studied margine are given in table 1 . The crystal structure of the bentonite was examined by X-ray diffraction (XRD) with $\mathrm{CuK} \alpha$ radiation. The quantitative mineralogical analysis was extracted from the powder XRD data using an internal standard for each mineral ( $\pm 5 \%)[21]$. Fourier transform infrared spectrometry (FTIR) was used to analyse the functional groups in the adsorbent. The spectra were

\footnotetext{
Corresponding author: hanane.aithmeid@gmail.com
} 
recorded on Shimadzu FTIR-8400S spectrometer using a finely ground $\mathrm{KBr}$ pellets with $2 \%$ of the sample recorded from 4000 to $400 \mathrm{~cm}^{-1}$ at a resolution of $2 \mathrm{~cm}^{-1}$. Elemental analysis of the sample was performed by Xray fluorescence. The morphology and size of the particules were observed by scanning electron microscopy (SEM).

Table 1. General characteristics of margine.

\begin{tabular}{|c|c|}
\hline Parameter & $\begin{array}{l}\text { Mean } \pm \text { standard } \\
\text { deviation }(n=3)\end{array}$ \\
\hline $\mathrm{pH}$ (Unit) & 4.03 \\
\hline $\mathrm{EC}(\mathrm{mS} / \mathrm{cm})$ & 16.93 \\
\hline $\operatorname{COD}\left(\right.$ g. $\left.\mathrm{L}^{-1}\right)$ & 172.72 \\
\hline TSS $\left(g . L^{-1}\right)$ & 5.93 \\
\hline NTK $\left(g \cdot L^{-1}\right)$ & 2.39 \\
\hline Total polyphenols $\left(\mathrm{g} \cdot \mathrm{L}^{-1}\right)$ & 9.17 \\
\hline Total phosphorus (mg. $\left.\mathrm{L}^{-1}\right)$ & 1.16 \\
\hline
\end{tabular}

Note: * EC $(\mathrm{mS} / \mathrm{cm})$ : Electrical conductivity ; COD $\left(\mathrm{g} . \mathrm{L}^{-1}\right)$ : Chemical Oxygen Demand; TSS (g.L $\left.\mathrm{L}^{-1}\right)$ : Total suspended solids; NTK (g.L $\left.\mathrm{L}^{-1}\right)$ : Total nitrogen Kjeldahl.

\subsection{Batch adsorption experiments}

We analyzed the efficacy of natural bentonite on organic matter and nutrients in the margine. For this purpose, 20, $40,50,70$ and $90 \%$ of bentonite was added to margine in $100 \mathrm{~mL}$ beakers. All experiments were performed at ambient temperature. The $\mathrm{pH}$ of the sample solution was determined by a $\mathrm{pH}$ meter according to the protocol described by Alkama et al (2009) [22, 23]. Total suspended solids are determined by filtration method AFNOR T90-105 [24]. The chemical oxygen demand analysis was carried out using closed reflux colorimetric method with potassium dichromate solution as oxidant and nano colour colorimeter [25]. Total polyphenols were measured using the method developed by Macheix et al (1990) [26]. Total phosphorus was determined according to standard methods by AFNOR (1997) [24]. Kjeldahl nitrogen was carried out using the protocol AFNOR T90-110.

To determine the remaining concentration and to calculate the percentage of organic matter and nutrients removal, the absorbance of solution was read at the wavelength of maximum dye using a UV-Vis spectrophotometer. Eq. (1) was used to determine the percentage of organic matter and nutrients removal:

$$
\text { Removal rate }(\%)=\left(C_{0}-C_{e} / C_{0}\right) \times 100
$$

Where $\mathrm{C}_{0}\left(\mathrm{mg} . \mathrm{L}^{-1}\right)$ is the initial concentration and $\mathrm{C}_{\mathrm{e}}$ $\left(\mathrm{mg} . \mathrm{L}^{-1}\right)$ is the equilibrium concentration.

\section{Results and discussion}

\subsection{Characterization of adsorbent}

\subsubsection{Characterization by $X$-ray diffraction}

The mineralogical composition (XRD) of raw bentonite and clay fraction of $<2 \mu \mathrm{m}$ are illustrated in Fig. 2. The raw bentonite consists essentially of montmorillonite (Mon), K-feldspar (K-fd), hematite (Hem), anorthite (An) and cristobalite $(\mathrm{Cr})$. Of which, secondary minerals grading less than $10 \%$, quartz $(\mathrm{Qz})$, anatase (At), calcite (C), Dolomite (Dl), pyrite (Pyr). Rhodochrosite (Rh), zeolite ( $\mathrm{Zl})$ and xenotime (Xn) are present in the sample as impurities. The clay fraction $(<2 \mu \mathrm{m})$ is mainly composed of smectite, illite and interlayers (Fig. 2 b)

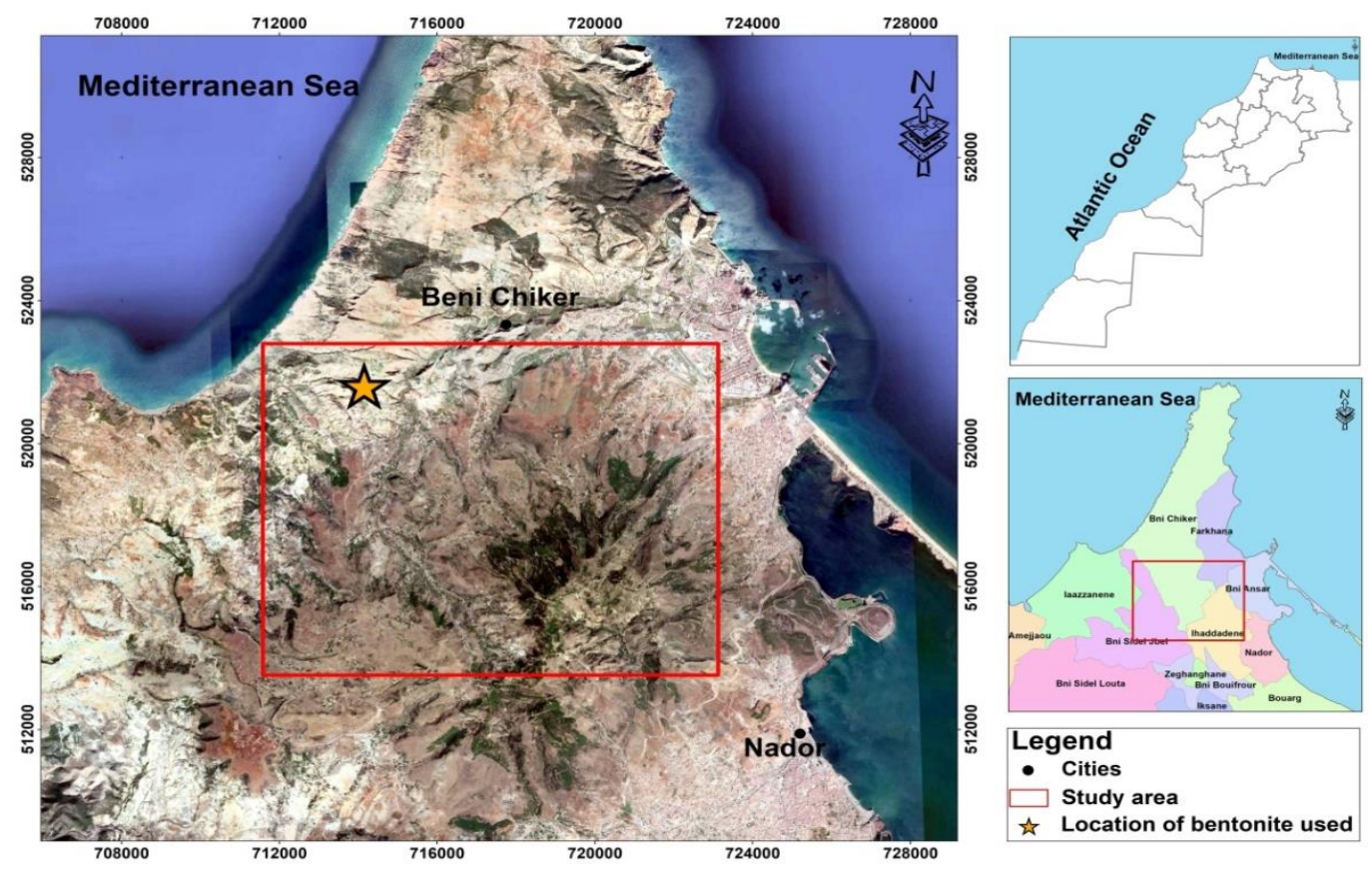

Fig. 1. Location map of the study area, North-East of Morocco. 


\subsubsection{Infrared spectral characteristics}

The FTIR spectra of the raw bentonite (Fig. 3), suggest a very strong multiple absorption band observed from 3643.53 to $3452.58 \mathrm{~cm}^{-1}$, coinciding with the elongation vibrations of the $\mathrm{OH}$ groups of the octahedral layer, characterizing smectites [27]. The band at $3452.58 \mathrm{~cm}^{-1}$ corresponds to the $\mathrm{O}-\mathrm{H}$ elongations of the waters [28]. The band at $2380 \mathrm{~cm}^{-1}$ corresponds to carbonates or bicarbonates and has not changed with hairiness [29]. The sample characterized by intense bands observed at $1035.77 \mathrm{~cm}^{-1}$ corresponds to the valence vibrations of the Si-O bond [30], has been attributed to tetrahedral silica in clay or quartz minerals [31]. The band at $912.23 \mathrm{~cm}^{-1}$ corresponding to Al-Al-OH. Absorption bands between $912.23 \mathrm{~cm}^{-1}$ and $700.16 \mathrm{~cm}^{-1}$, related to the vibrations of $\mathrm{Al}-\mathrm{Al}-\mathrm{OH}, \mathrm{Al}-\mathrm{Fe}-\mathrm{OH}$ and $\mathrm{Al}-\mathrm{Mg}-\mathrm{OH}$, which confirm the presence of a dioctahedral smectite [31]. The 800.46 $\mathrm{cm}^{-1}$ strip is attributed to Al-Mg-OH deformations. All low bands from 547.78 to $443.63 \mathrm{~cm}^{-1}$ corresponding to the deformation of Al-O-Si, Si-O-Mg and Si-O-Si of clay minerals [32]. The set of low bands that appeared between 1100 and $1000 \mathrm{~cm}^{-1}$ corresponding to the $\mathrm{Si}-\mathrm{O}$ bands [29].

\subsubsection{Chemical composition}

As shown in Table 2, the chemical composition affected the amounts of natural bentonite. Besides, the bentonite used is mainly characterized by $\mathrm{Fe}, \mathrm{Ca}, \mathrm{Si}$ and $\mathrm{Al}$. In contrast the $\mathrm{K}, \mathrm{P}, \mathrm{S}, \mathrm{Ti}, \mathrm{Rb}, \mathrm{Sr}, \mathrm{Zr}$, Th, Zn and $\mathrm{Y}$ very low (less than $1 \%$ ).

\subsubsection{Morphological characterization (SEM)}

Scanning electron microscopy images will contribute to surface examination of the materials. To this end, SEM images were taken of the sample (Fig. 4). According to fig. $4 \mathrm{a}$, reveals the porous charactristics ans surface texture of bentonite particles. It is apprent the petaloid aggregates of the grains in spherical form with heterogeneous dimensions. We observe irregularly shaped pores and fissurations.

It could be easily deduced these pores play a major role in the removal of the organique matter and nutrients $[33,34]$. Raw bentonite sample contains accessory phases as feldspar and iron oxide.

The energy-dispersive X-Ray Spectroscopy (EDX spectrum) obtained, shows the presence of the following elements: aluminum (Al), silicon $(\mathrm{Si})$, magnesium $(\mathrm{Mg})$, sodium $(\mathrm{Na})$, Oxygen $(\mathrm{O})$, potassium $(\mathrm{K})$, iron $(\mathrm{Fe})$, and calcium (Ca) (Fig. 4 b).

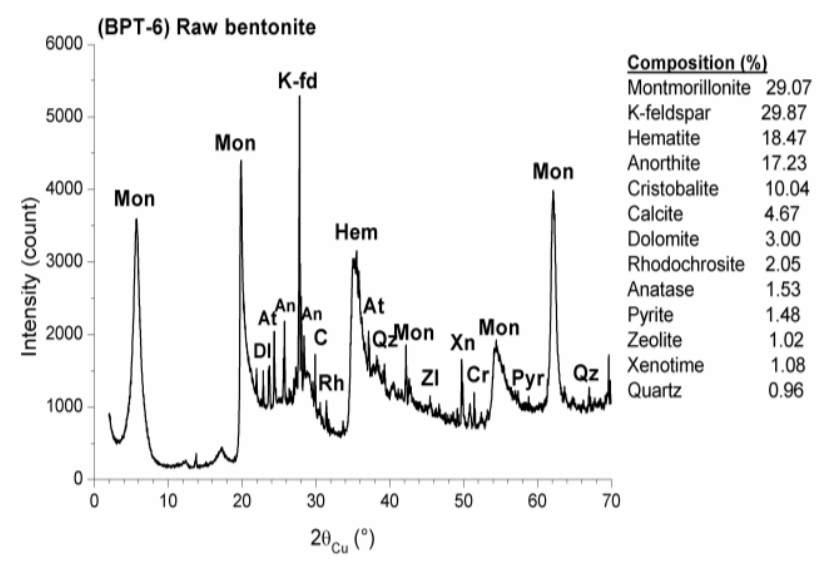

Fig. 2 a. XRD patterns of raw bentonite.

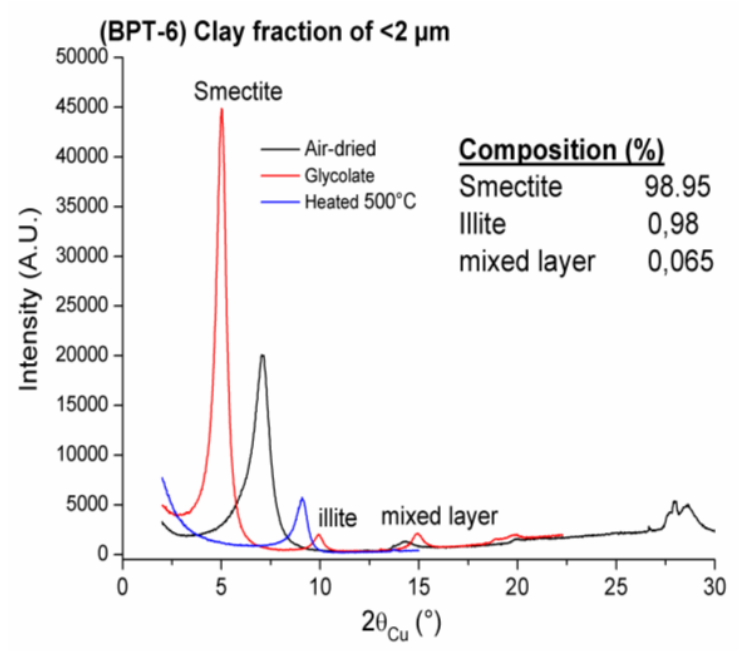

Fig. 2 b. XRD patterns of $<2 \mu$ m of clay fraction.

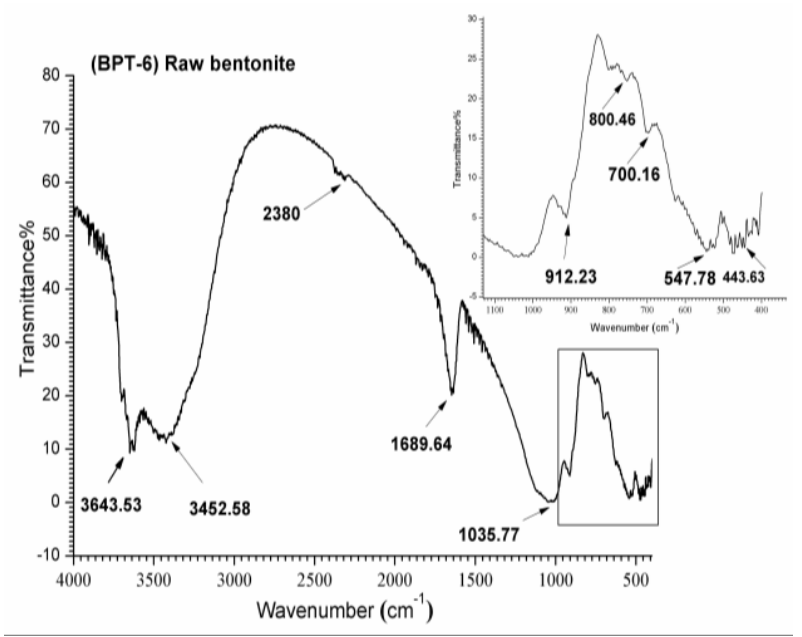

Fig. 3. FTIR spectra of raw bentonite.

Table 2. Chemical composition of natural bentonite

\begin{tabular}{llllllllllllllll}
\hline Element & $* \mathrm{Fe}$ & $\mathrm{K}$ & ${ }^{*} \mathrm{Ca}$ & ${ }^{*} \mathrm{Si}$ & $* \mathrm{Al}$ & $\mathrm{P}$ & $\mathrm{S}$ & $\mathrm{Ti}$ & $\mathrm{Rb}$ & $\mathrm{Sr}$ & $\mathrm{Zr}$ & $\mathrm{Th}$ & $\mathrm{Zn}$ & $\mathrm{Y}$ \\
\hline Wt.\% & 41.09 & 5.74 & 17 & 14.83 & 11.05 & 4.09 & 1.97 & 2.66 & 0.05 & 0.58 & 0.58 & 0.177 & 0.1 & 0.043 \\
\hline
\end{tabular}

(*) : maine composition 
a. (BPT-6) Raw bentonite

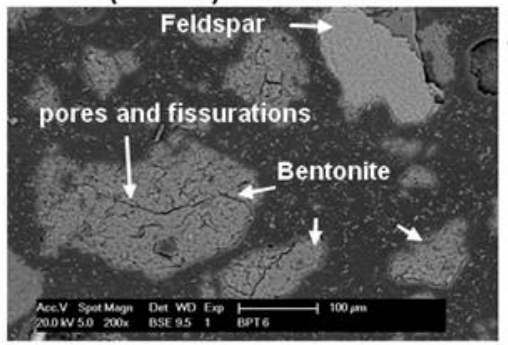

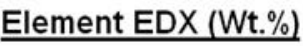

- Feldspar

O 31.02

$\mathrm{Na} \quad 1.09$

Al $\quad 7.57$

Si 21.64

K $\quad 9.51$

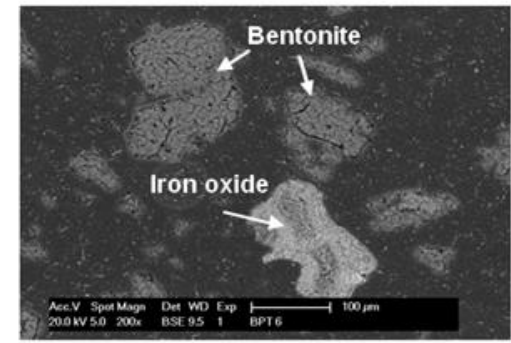

Element EDX (Wt.\%)

- Bentonite

O 28.33

$\mathrm{Mg} \quad 1.58$

Al $\quad 11.31$

Si $\quad 19.13$

- Iron oxide

O $\quad 56.35$

$\mathrm{Fe} \quad 24.99$

\section{b. Energy-dispersive X-ray spectroscopy}
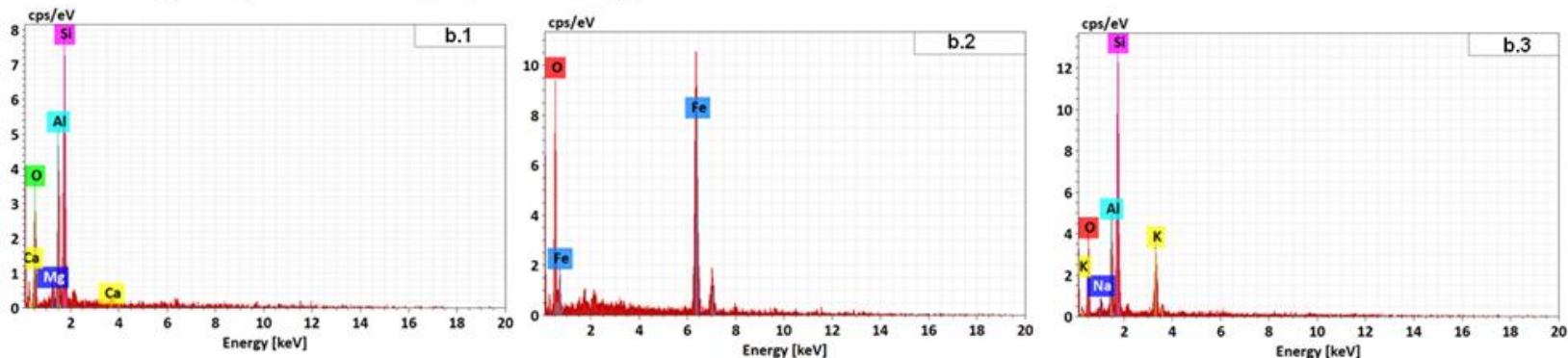

Fig. 4. (a) SEM images of bentonite ; (b) EDX spectra (b.1) bentonite, (b.2) iron oxide, (b.3) feldspar.

\subsection{Removal rate}

\subsubsection{Effect of bentonite on $\mathrm{pH}$ and $\mathrm{EC}$}

Figure 5 and table 3 shows the values of the electrical conductivity and the $\mathrm{pH}$ variations during the treatment of the margines. The $\mathrm{pH}$ is one of the parameters that greatly affect both aqueous chemistry and surface active sites of the bentonite [34].
As seen in fig.5, the $\mathrm{pH}$ increase of 8.04 at higher bentonite percentage $(90 \%)$ was lower than

that at lower bentonite percentage $(20 \%)$, which could be interpreted as being due to surface charge of the bentonite. The bentonite surface mainly oxygencontaining groups linked to the $\mathrm{H}^{+}$(Fig. 3 and 4 b), is positively charged and anionic the organic matter and nutrients adsorption occurs easily. On the contrary, when the bentonite at higher percentage the electrical conductivity decrease.

Table 3. Mean concentraton and $\%$ removal of parameters analysed.

\begin{tabular}{|c|c|c|c|c|c|c|c|}
\hline \multirow[b]{3}{*}{ DCO } & \multirow[b]{3}{*}{$(\mathrm{g} / \mathrm{l})$} & \multirow{3}{*}{$\begin{array}{l}\text { OMW } \\
172.72\end{array}$} & \multicolumn{5}{|c|}{ Percentage of bentonite (\%) } \\
\hline & & & 20 & 40 & 50 & 70 & 90 \\
\hline & & & 154.02 & 130.98 & 105.7 & 96.4 & 29.71 \\
\hline & $(\%)$ & - & 10.83 & 24.17 & 38.8 & 44.19 & 82.8 \\
\hline \multirow[t]{2}{*}{ SST } & $(\mathrm{g} / \mathrm{l})$ & 5.93 & 5.75 & 5.61 & 5.35 & 5.18 & 3.82 \\
\hline & $(\%)$ & - & 3.04 & 5.4 & 9.78 & 12.65 & 35.58 \\
\hline \multirow[t]{2}{*}{ TKN } & $(\mathrm{g} / \mathrm{l})$ & 2.39 & 2.18 & 2 & 1.64 & 1.22 & 0.05 \\
\hline & $(\%)$ & - & 8.79 & 16.32 & 31.38 & 48.95 & 97.91 \\
\hline \multirow[t]{2}{*}{ Phl } & $(\mathrm{g} / \mathrm{l})$ & 9.17 & 8.62 & 8.16 & 7.18 & 5.85 & 3.83 \\
\hline & $(\%)$ & - & 6 & 11.01 & 21.7 & 36.21 & 58.23 \\
\hline \multirow[t]{2}{*}{$\mathbf{T P}$} & $(\mathrm{g} / \mathrm{l})$ & 1.16 & 0.76 & 0.65 & 0.61 & 0.49 & 0.29 \\
\hline & $(\%)$ & - & 34.48 & 43.97 & 47.41 & 57.76 & 75 \\
\hline pH & (Unit) & 4.03 & 4.28 & 5.06 & 5.63 & 6.19 & 8.04 \\
\hline EC & $(\mathrm{mS} / \mathrm{cm})$ & 16.93 & 14.82 & 10.04 & 8.82 & 5.92 & 0.17 \\
\hline
\end{tabular}

*OMW: Oil mill liquid waste 


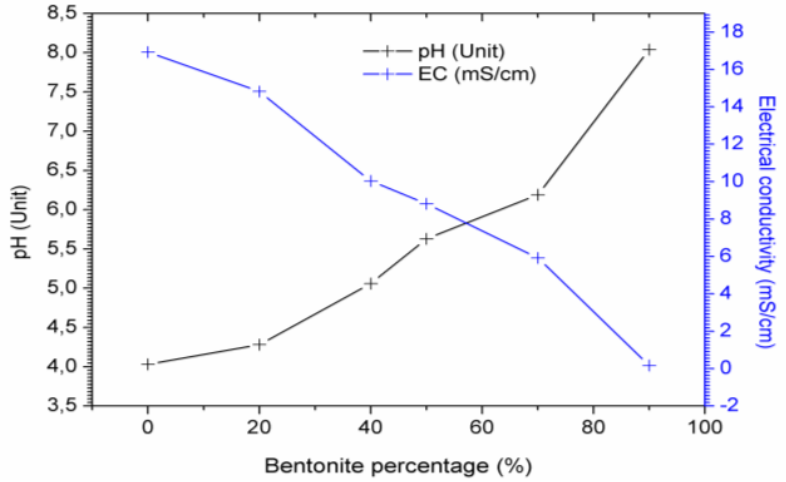

Fig. 5. $\mathrm{pH}$ and EC variation during treatment of OMW.

\subsubsection{Effect of bentonite on the reduction of organic matter and TKN}

The results obtained in this study show a significant difference in the percentages and concentrations reduction of COD (Fig. 6). Dissolved oxygen COD concentrations were decreased as the percentage of bentonite increased from 172.72 to $29.71 \mathrm{~g} / \mathrm{l}$, with a maximum reduction rate of $82.8 \%$. Organic matter is reduced by a combination of biological degradation.

The reduction was due to the degradation and conversion of organic compounds into biogas [35].

The reduction of nitrogen TKN concentration during the treatment of margine is shown in Fig. 7and table 3 successively. The maximum rate of TKN reduction in this phase is $97.91 \%$. The general decreases in the TKN indicate their development of anaerobic conditions and denitrification process [34].

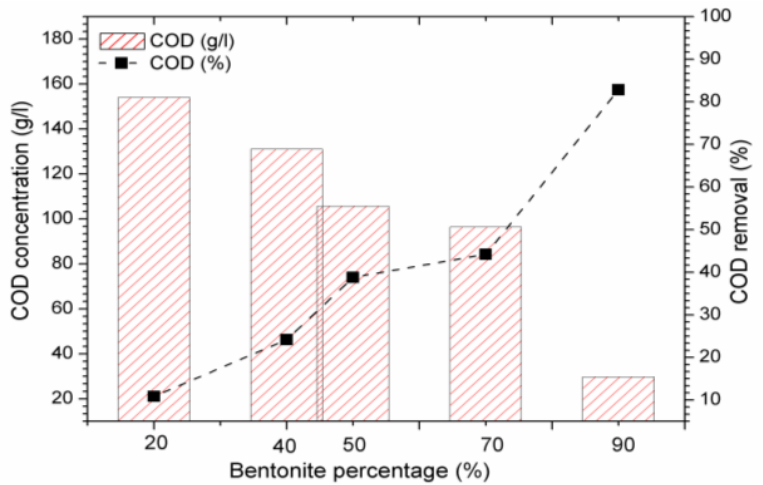

Fig. 6. Reduction and concentration of COD during treatment of OMW.

\subsubsection{The nutrients reduction}

The reduction of nutrient concentration during the treatment of margine is shown successively in Fig. 8 and Fig. 9. The general decrease in phosphorus (Tp) concentration from 1.16 to $0.29 \mathrm{~g} / \mathrm{l}$, where the maximum rate of $\mathrm{Tp}$ removal reached $75 \%$. Thus, the high decrease in this study is attributable to composition chemical of bentonite (table 2). The metallic iron in bentonite plays a crucial role in the removal of Tp by the precipitation process. Alternatively, the concentration reduction of polyphenols ( $\mathrm{Phl}$ ) from 9.17 to $3.83 \mathrm{~g} / \mathrm{l}$ on the $58.23 \%$ removal rate, were recorded the percentage of bentonite $99 \%$. Indeed, the decrease in phenolic compounds would be related to the greater and/or an increase in $\mathrm{pH}[24,23]$.

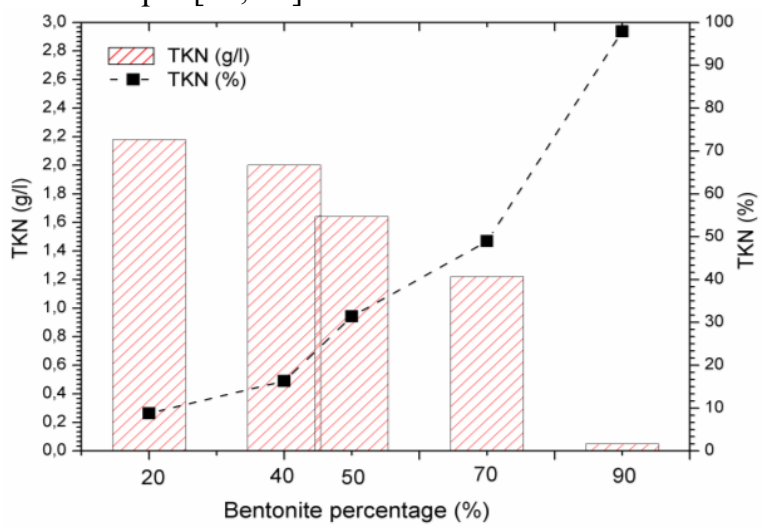

Fig. 7. Reduction and concentration of TKN during treatment of OMW.

\subsubsection{The SST reduction}

In the present study, the total suspended solids (SST) concentration reduced from 5.93 to $3.82 \mathrm{~g} / \mathrm{l}$, with a removal rate maximum of $35.58 \%$. However, the reduction rate of the SST is highly influenced by heterogeneous dimensions and varied mineralogical compositions (shown in Fig. 2a and 4a respectively).

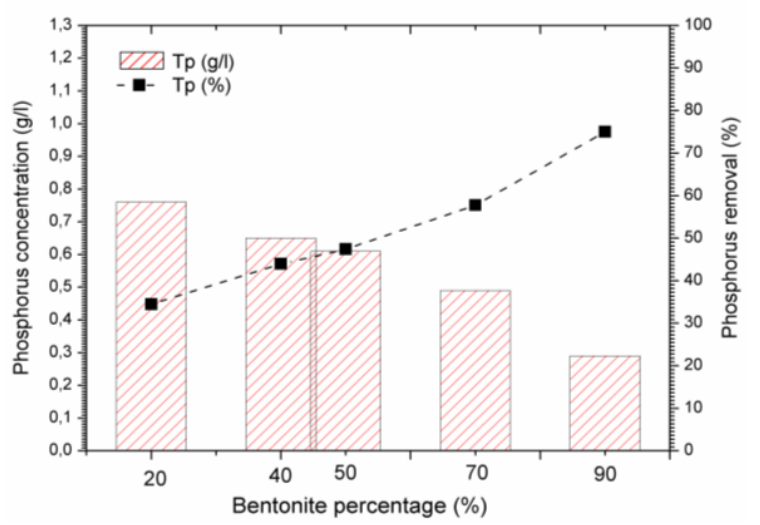

Fig. 8. Concentration and reduction in Tp during treatment of OMW.

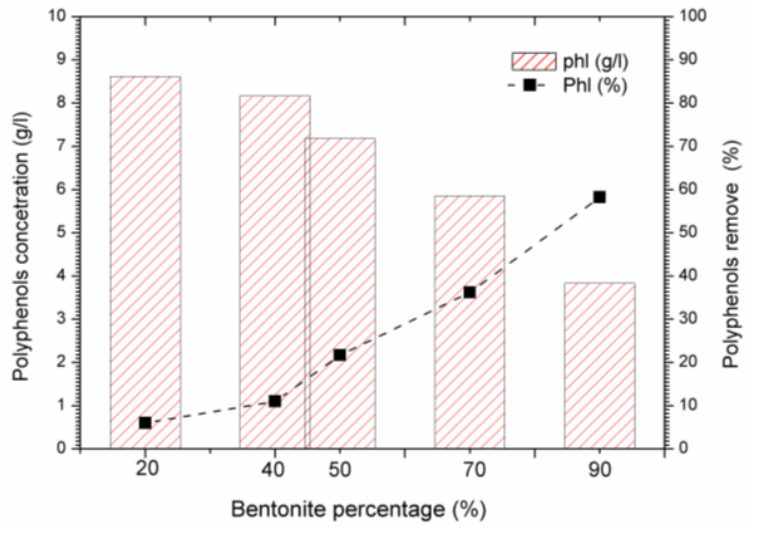

Fig. 9. Concentration and reduction in Phl during treatment of OMW. 


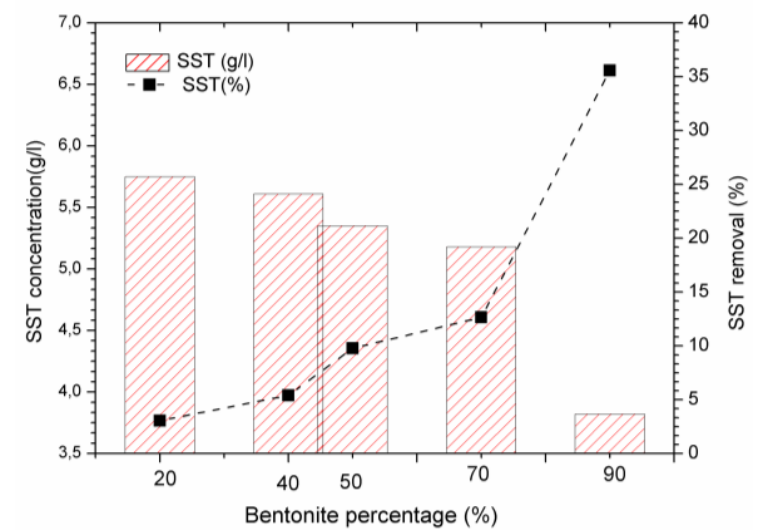

Fig. 10. Concentration and reduction in SST during treatment of OMW.

\section{Conclusion}

This work discriminated the application of Moroccan bentonites in the environmental field. First of all, we allowed to characterize the bentonite used such as adsorbant of point of view mineralogical, chemical and morphological structure. Calcium bentonite shows a significant capacity to remove the organic load and nutrients during treatment of margine.

Taking into consideration all the results obtained in this work, we concluded that the presence of free sites on the surface of the bentonite particles, which corresponds to the progressive crease in removal rates of organic matter and nutrients.

Given the raw calcium bentonite has been successfully applied for elimination of organic matter and nutrients, this work opens the way for futher research to better understand the adsorption mechanism of heavy metal removal from margine.

\section{Compliance with ethical standards}

Conflict of interest On behalf of all authors, the corresponding author states that there is no conflict of interest.

Acknowledgements We thank the anonymous reviewers for their remarks which have helped improve the manuscript.

\section{References}

1. D. Carroll, Clay minerals: a guide to their X-ray identification, Geological Society of America, 126(1970).

2. H. H. Murray, Appl. Clay Sci., 17, 207-221 (2000).

3. W. M. Sutherland, Wyoming Bentonite, Summary report, Wyoming State Geological Survey (2014).

4. D. L. Rath, Public Inf. Circ., 25, 84-90 (1986).

5. W. D. Huff, American Mineralogist, 101,43-70 (2018).

6. M. Zhou, T. Luo, W.D. Huff, S. Liu, Journal of
Sedimentary Research, 84, 842-853 (2014).

7. M. Ddani, A. Meunier, M. Zahraoui, D. Beaufort, M. El Wartiti, C. Fontaine,B. Boukili, B. El Mahi, Clays and Clay Minerals, 53(3), 250-267 (2005).

8. A. López-Galindo, C. Viseras, P. Cerezo, Appl. Clay Sci., 36(1-3), 51-63 (2007).

9. B. Belkacem, J. Chem. Chem. Eng., 5(7), 624 (2011).

10. L. D. Maxim, R. Niebo, E. E. McConnell, Inhal. Toxicol., 28(13), 591-617 (2016).

11. A. G. Clem, R. W. Doehler, Clays Clay Miner., 10(1), 272-283 (1961).

12. J. A. Alexander, M. A. Ahmad Zaini, A. Surajudeen, E.-N. U. Aliyu, A. U. Omeiza, Part. Sci. Technol., 37(5), 538-549 (2019).

13. Q. H. Hu, S. Z. Qiao, F. Haghseresht, M. A. Wilson, G. Q. Lu, Ind. Eng. Chem. Res., 45(2), 733-738 (2006).

14. W. Ling, Q. Shen, Y. Gao, X. Gu, Z. Yang, Soil Res., 45( 8), 618-623 (2008).

15. F. Ayari, E. Srasra, M. Trabelsi-Ayadi, Desalination, 206(1-3), 270-278 (2007).

16. D. B. Dunn, J. H. Hitchborn, Virology, 25(2), 171192 (1965).

17. H. Ait Hmeid, M. Akodad, M. Aalaoul, M. Baghour, A. Skalli, L. Daoudi, International Journal of Development Research, 10, 38714-38722 (2020).

18. H. Ait Hmeid, M. Akodad, M. Aalaoul, M. Baghour, A. Moumen, A. Skalli, A. Anjjar, P. Conti, A. Sfalanga, F. Ryazi Khyabani, S. Minucci, L. Daoud, Geological Society, London, 502, (2020).

19. H. Ait Hmeid M. Akodad, M. Aalaoul, M. Baghour, A. Moumen, A. Skalli, L. Daoudi Mater. Today Proc., 13, 505-514 (2019).

20. H. Ait Hmeid, M. Akodad, M. Baghour, M. El Gattafi, A. Moumen, L. Daoudi, M. Aalaoul, EuroMediterranean Conference for Environmental Integration, 1169-1172 (2018).

21. H. E. Cook , P. D. Johnson, J. C. Matti, I. Zemmels, D. E. Hayes, L. A. Frakes, A. G. Kaneps , Methods of sample preparation and X-ray diffraction data analysis, X-ray Mineralogy Laboratory, Deep Sea Drilling Project, University of California, Riverside, (1975).

22. N. Alkama, E. B. B. Bolou, H. Vailhe, L. Roger, S. M. Ounane, J. J. Drevon, Soil Biol. Biochem., 41(9), 1814-1823 (2009).

23. L. Latrach, N. Ouazzani, T. Masunaga, A.Hejjaj, K. Bouhoum, M. Mahi, L. Mandi ,Ecol. Eng., 91, 294301 (2016).

24. N. Ouazzani, K. Bouhoum, L. Mandi, L. Bouarab, K. Habbari, F. Rafiq, J. Schwartzbrod, Water Science and Technology, 31(12), 75-80 (1995).

25. J. Mabuza, B. Otieno, S. Apollo, B. Matshediso, Euro-Mediterranean J. Environ. Integr., 2(1), 1-10 (2017). 
26. A. Mansouri, G. Embarek, E. Kokkalou, P. Kefalas, Food., Chem., 89(3), 411-420 (2005).

27. B. Caglar, O. Cubuk, E. Demir, F. Coldur, M. Catir, C. Topcu, A. Tabak, J. Mol. Struct., 1089, 59-65 (2015).

28. E. Eren, B. Afsin, J. Hazard. Mater., 151(2), 682691 (2008).

29. W. K. Mekhamer, J. Saudi Chem. Soc., 14( 3), 301306 (2010).

30. I. Belbachir, B. Makhoukhi, Journal of the Taiwan Institute of Chemical Engineers,75, 105-111(2017).

31. O. Acisli, A. Khataee, S. Karaca, M. Sheydaei, Ultrason. Sonochem., 31, 116-121 (2016).

32. L. Karimi, A. Salem, J. Ind . Eng. Chem., 17(1), 9095 (2011).

33. L. M. Alhallak, S. Tirkes, Rapid Prototyping Journal, 7, 1305-1312 (2020).

34. R. Ben, S. Karoui, K. Karine, M. Achraf, EuroMediterranean J. Environ. Integr., 2(1), 20 (2017).

35. B. Shehu, U. Ibn, N. Ismail, Journal of engineering and applied sciences, 7(2), 169-172 (2012). 